The Journal of Laryngology \& Otology

http://journals.cambridge.org/JLO

Additional services for The Journal of Laryngology \& Otology:

Email alerts: $\underline{\text { Click here }}$

Subscriptions: $\underline{\text { Click here }}$

Commercial reprints: $\underline{\text { Click here }}$

Terms of use : $\underline{\text { Click here }}$

\title{
Is undergraduate otorhinolaryngology teaching relevant to junior doctors working in accident and emergency departments?
}

A Sharma, K Machen, B Clarke and D Howard

The Journal of Laryngology \& Otology / Volume 120 / Issue 11 / November 2006, pp 949 - 951

DOI: 10.1017/S0022215106002246, Published online: 31 July 2006

Link to this article: http://journals.cambridge.org/abstract_S0022215106002246

How to cite this article:

A Sharma, K Machen, B Clarke and D Howard (2006). Is undergraduate otorhinolaryngology teaching relevant to junior doctors working in accident and emergency departments?. The Journal of Laryngology \& Otology, 120, pp 949-951 doi:10.1017/S0022215106002246

Request Permissions : $\underline{\text { Click here }}$ 


\title{
Is undergraduate otorhinolaryngology teaching relevant to junior doctors working in accident and emergency departments?
}

\author{
A Sharma, K Machen, B Clarke, D Howard
}

\begin{abstract}
Undergraduate ENT teaching provides junior doctors with skills and knowledge useful for the practice of medicine. However, ENT has been removed from the curriculum of nine of the 29 medical schools in the United Kingdom, as it was not deemed relevant to general medical practice. A telephone survey was performed of 20 senior house officers working in accident and emergency (A\&E) departments across the United Kingdom. The results showed that 90 per cent felt their undergraduate ENT teaching was directly beneficial to working in A\&E, 75 per cent felt they had not received enough undergraduate ENT teaching and 45 per cent currently received no postgraduate teaching whilst working in A\&E.

These results illustrate the importance of ENT teaching in the undergraduate curriculum and its value to practising doctors. They highlight the fact that prospective studies are required to examine the effect on junior doctors of changing the curriculum.
\end{abstract}

Key words: Undergraduate Medical Education; Otolaryngology

\section{Introduction}

Modern medical education in the United Kingdom is currently being reformed, with the General Medical Council aiming to produce a larger volume of doctors each year. It is intended that those graduating will be practically competent and be able to deliver efficient, realistic health care to the population they serve. Medical courses are becoming streamlined in an attempt to teach those general skills viewed to be most relevant to a practising junior doctor. For those wishing to progress to hospital consultant, the teaching of specialized skills will be done at a postgraduate level, during the Foundation Programme. But are these changes in the curriculum of any actual benefit to the doctors they produce? The changes seem sensible, and have a sound logic underpinning them, but there are as yet no outcome measures of the new curriculum. There has been no prospective study on the cohort of doctors affected by this intervention.

Currently in the UK, nine medical schools have removed from their curriculum formalized teaching in ear, nose and throat medicine and head and neck surgery. Although motivated students may opt to study this area in a special module, a proportion of doctors currently in training will graduate having received no ENT teaching. The remaining medical schools place varying degrees of importance on this clinical topic. Twelve schools have no clinical attachment to a specified consultant-led team, and three provide only lectures. ${ }^{1}$ Other schools have integrated ENT teaching into combined attachments with other specialties, such as ophthalmology and dermatology. ${ }^{2}$ Separate training in ENT has been shown to produce improved clinical results in trainees. Fisher and Pfleiderer showed that including just one additional seminar on otoscopy for medical students could have a profound effect on their clinical ability; medical students were found to have better gains in confidence and skill when compared with a group which did not receive this additional seminar. ${ }^{3}$ Therefore, students who graduate with little or no ENT teaching may be at a noticeable disadvantage.

\section{Method}

A short study was formulated to examine junior doctors' views on the reduction in formalized ENT teaching at medical school. A telephone survey was carried out of senior house officers (SHOs) working in accident and emergency (A\&E) departments across the UK. Junior doctors' SHO years place a great deal of responsibility on the individual doctor for the first time, with decisions about immediate patient care often being made alone. It would be in these posts that doctors may first recognize the deficits in their undergraduate ENT training. The

From the Royal National Throat, Nose and Ear Hospital, Institute of Laryngology and Otology, University College London, London, UK.

Accepted for publication: 23 February 2006. 
telephone questionnaire consisted of 10 questions (see Table I).

\section{Results}

Twenty SHOs, practising in different, randomly selected hospitals, were interviewed by telephone. The response rate was 100 per cent. Each respondent had had a good experience of dealing with ENT cases in $\mathrm{A} \& \mathrm{E}$, the average case load being eight cases per day (range two to 20). Fifteen doctors had access to a specialist ENT SHO if required; however, the doctors reviewed all patients independently prior to referral.

The doctors originated from 16 of the then 27 UK medical schools. With the surge in demand for medical practitioners, there are now 29 medical schools in the UK, but only 27 had students who had graduated at the time of this study (march 2004). Respondents' median graduation date was 2002 (range 1997 to 2003). The average amount of undergraduate ENT teaching received was 13.7 days, ranging from one day of lectures to four weeks of tutorials and clinics. Two of the doctors received no ENT teaching at all. Only eight (40 per cent) of the doctors had experience on a Consultant-led team firm within a teaching hospital. When asked whether they felt they had received enough ENT experience as an undergraduate, 15 (75 per cent) said they had not. When asked whether their ENT teaching was of direct benefit to working in A\&E, 18 (90 per cent) said that it was. All 20 of the doctors interviewed felt that ENT teaching had a place in the medical curriculum.

\section{Discussion}

It has been shown that the majority of doctors find their undergraduate ENT training of use in A\&E, and many feel that they did not receive enough ENT teaching at medical school. This certainly creates a strong argument for the inclusion of ENT teaching somewhere in the medical course. Given that some medical schools do not allocate time to a clinical ENT attachment, perhaps these skills and knowledge could be learnt elsewhere? Could time at medical school be saved by passing the responsibility for ENT teaching elsewhere?

\section{TABLE I}

QUESTIONNAIRE

(1) What medical school did you attend?

(2) What year did you graduate?

(3) How many ENT patients do you see on average per week?

(4) Do you see them all yourself, or do you refer directly to an SHO in ENT?

(5) How much ENT teaching did you receive at medical school?

(6) What format did this teaching take?

(7) Do you receive any formal teaching currently as an SHO in A\&E?

(8) Do you find your undergraduate ENT teaching of direct benefit whilst working in A\&E?

(9) Do you feel you received enough ENT teaching as an undergraduate?

(10) Do you think ENT has a place in the medical school curriculum?
Four (20 per cent) of the doctors interviewed felt that they were exposed to plenty of ENT pathology during attachment to a general practice. Whilst this would be true for those students lucky enough to experience a breadth of patient contact, for others it would limit their experience to commonly encountered conditions such as middle-ear infections and rhinitis. Indeed, respondents' statements that they felt they had received enough teaching may have been due to an ignorance of the range of conditions affecting the head and neck. With no structured teaching, there would be large gaps in students' knowledge. Some of the doctors interviewed in the survey commented on the wealth of clinical experience imparted by general practitioners (GPs). Whilst this may be true, the amount of factual knowledge gained may be small. Fisher and Pfleiderer ${ }^{4}$ demonstrated that medical students were better at identifying specific features of the tympanic membrane than GPs $(p<0.01)$. Additionally, GP surgeries do not usually have the facilities to teach ENT, as the demonstration of physical signs is difficult without fibre-optic equipment and television linkage with microscopes. 5

Another option for ENT teaching would be to postpone it until a more clinically relevant time. Hospital postgraduate departments arrange regular afternoon or lunchtime teaching sessions for the training of junior doctors. By delegating the responsibility to hospital trusts, ENT teaching could be left out of the medical school curriculum. All of those surveyed felt that A\&E SHOs should be given postgraduate ENT teaching. However, nine (45 per cent) of the SHOs had received no postgraduate teaching at all. Training sessions on an ENT topic were provided for nine (45 per cent) respondents, with the lesson lasting between two and four hours. This is far less than the minimum of one day offered at most medical schools. The large number of hospitals in the UK makes any form of standardized teaching difficult, whereas the smaller number of medical schools provides a better opportunity to train and assess ENT-based skills and knowledge.

- This study used a relatively non-specific tool to investigate the attitudes of newly qualified doctors to their undergraduate ENT teaching

- The junior doctors interviewed felt that they had insufficient undergraduate ENT teaching and that postgraduate teaching was patchy

- The junior doctors felt that ENT teaching was still relevant in the undergraduate curriculum. This message needs to be taken into account by those responsible for designing the undergraduate medical curriculum

\section{References}

1 Frampton S, Kwame I. Otorhinolaryngology - head and neck surgery in the undergraduate curriculum. ENT News 2005;13:39-40 
2 Mace AD, Narula AA. Survey of current undergraduate otolaryngology training in the United Kingdom. $J$ Laryngol Otol 2004;118:217-20

3 Fisher E, Pfleiderer A. Is undergraduate otoscopy teaching adequate? An audit of clinical teaching. $J R$ Soc Med 1992;85:23-5

4 Fisher E, Pfleiderer A. Assessment of the otoscopic skills of general practitioners and medical students: is there room for improvement? Br J Gen Pract 1992; 42:65-7

5 Lund VJ. Otolaryngology in the curriculum - 10 years on: discussion paper. $J$ R Soc Med 1990;83:337-9
Address for correspondence:

Mr Ashish Sharma,

Flat 18 Grafton Yard,

Kentish Town,

London NW5 2NF, UK.

E-mail: Ashish@cantab.net

Mr A Sharma takes responsibility for the integrity of the content of the paper.

Competing interests: None declared 